\title{
Using Remote Sensing and GIS for mapping and monitoring marine habitats in Nabq (MRPA), South Sinai, Egypt
}

\author{
Abdel-Kader M. Hassan ${ }^{1}$; Sameh B. El-Kafrawy ${ }^{2}$; Mohammad A. El-Gharbawy ${ }^{2}$ \\ Mohamed Abou-Zaid ; Mahmoud H. Ahmed ${ }^{2}$ \\ 1- Zoology Department, Faculty of Science, Al-Azhar University, Cairo, Egypt. \\ 2- Marine Science Department, National Authority of Remote Sensing and Space Science, \\ Cairo, Egypt. \\ abouzaid_mohamed@yahoo.com
}

\begin{abstract}
Egypt has sought to protect its natural resources and marine biodiversity that are located in the Gulf of Aqaba by establishing a network of Marine Protected Areas. Nabq Managed Resources Protected Area (NMRPA) is the biggest marine protectorate exists in the region and characterized by the great diversity of habitats and ecosystems in a uniquely compact setting, representing a complete terrestrial/ marine ecosystem characteristic of the Gulf of Aqaba coast. The applying of advanced technologies such as Remote Sensing (RS) and Geographic Information System (GIS) in recognizing the changes in the coastal zone habitats in the area; gave us the ability to map and monitor the amount and the causes of changes in the habitats in a specific, fast, accurate and a relatively low-cost alternative to traditional field studies. Using a time series of four imageries; three (SPOT-4) imageries dated 2006, 2009 and 2010 beside one (Quick-Bird) imagery dated 2010; we explored the utility of temporal texture as a diagnostic tool to detect ecological changes in coastal zone habitats. We used a time series of imageries to calculate the temporal variation in the brightness of each pixel, rather than statistically placing each pixel into a specific habitat class. Insitu fieldwork on Nabq (MRPA) coastal zone confirmed that, the mangrove stock has developed, sea-grass habitat has developed from year to year too and the coral reef habitat has been degraded. We propose that the further development of such remote sensing techniques will lead to the establishment of an index of habitat variability. Such an index could alert resource managers to potential problems on coastal zone habitat otherwise would go undetected.
\end{abstract}

Keywords: Remote Sensing, GIS, SPOT-4, Quick-Bird, Nabq, change detection, ecosystem monitoring, time series, Gulf of Aqaba, Egypt.

\section{INTRODUCTION}

The Red Sea represents a complex and unique tropical marine ecosystem with extra-ordinary biological diversity and a remarkable high degree of endemism. This long narrow body of water separates north-east Africa from the Arabian Peninsula. The Red Sea contains representatives of all the major tropical marine communities except estuaries, which cannot form because it receives no permanent rivers (PERSGA, 2004).

The primary environmental "hot spot" of the Red Sea is the Gulf of Aqaba; which is $170 \mathrm{~km}$ long and 14-26 km wide and forms part of the Afro-Syrian Rift System with steep walls dropping to great depths $(2,000 \mathrm{~m}$ in places). It is separated from the Red Sea by 6-kilometer wide Straits of Tiran (Chiffings, 2003).

As a result of its semi-enclosed nature, the Gulf of Aqaba is threatening serious degradation as a result of marine pollution, physical destruction and unsustainable 
exploitation of marine and coastal natural resources. The Gulf of Aqaba natural resources provide a sustainable environmental and economical support for the region; hence, the marine and coastal environment should be well protected from the adverse impacts of pollution and unsustainable exploitation to ensure the sustainable use of its resources and good health of people (PERSGA, 2004).

The environmental and economical importance of the Gulf of Aqaba, led the Egyptian Decision maker to declare protected areas in this region, in order to preserve and conserve these contrasting ecosystems, rich and unique biodiversity, its production, its conservation and recreational values (Baha El Din, 1998).

The huge development surge that Egypt is witnessing, putting unprecedented pressures on the natural resources of Egypt, degrading many areas very rapidly and threatening some with complete eradication. The resource base for this and future generations is being eroded and lost. As we know that; the nation's future is depend on the wise and sustainable use of its natural resources, which are the basis for all economic activities in the country, the protection of the nation's natural resources becomes an absolute necessary (Baha El Din, 1998).

Nabq Managed Resources Protected Area (NMRPA) was established (IUCN PA management category VI) in 1992 by the Law N. 102 of 1983, prime ministerial decree 1511 for 1992 declaration of the area, and declaration of the whole Gulf of Aqaba (Egyptian Side) a natural protectorate. The area has a total surface area of $586.5 \mathrm{~km}^{2}$ (land portion: $464.6 \mathrm{~km}^{2}$; marine portion: $121.9 \mathrm{~km}^{2}$, in which five closed areas cover $97.27 \mathrm{~km}^{2}$ ). The PA includes a variety of marine habitats, having one of the northern-most mangrove Avicennia marina communities in the world, coral reefs and sea-grass. The marine portion of NMRPA falls under four management zones of varying protection levels: strict natural zone, no-take zone, recreational zone and multiple use zone. The strict natural zone (marine $91.27 \mathrm{~km}^{2}$ ) includes a scientific reserve for about $15 \mathrm{~km}$ of the coastline where all activities are prohibited except scientific research. While four NTZs (marine $6 \mathrm{~km}^{2}$ ) cover about $5 \mathrm{~km}$ of the coastline where all fishing is prohibited, recreational activities (boating, scuba diving, snorkelling, reef walking), and scientific research are permitted (Mabrouk, 2007).

Satellite imageries have immensely helped mapping of coastal ecosystems and provided estimates of extent and alteration in land cover in coastal ecosystem. Information on coastal habitat (critical/vital) and associated shore land features along the entire coast has been carried out through visual interpretation of multi-spectral data for macro-level planning for many countries (Nayak et al., 1991; Jagtap et al., 2001; Nayak, 2002).

The current study aims to test the applying of advanced technologies such as Remote Sensing (RS) and Geographic Information System (GIS) in recognizing the changes in the coastal zone habitats in both quantitative and qualitative ways.

\section{MATERIALS AND METHODS}

\section{The Study area position and description:}

Nabq managed resources protected area is situated in the west side of the Gulf of Aqaba, about $35 \mathrm{~km}$ to the north of Sharm El Sheikh $\left(34.42730^{\circ} \mathrm{E}\right.$ and $\left.28.09110^{\circ} \mathrm{N}\right)$. It extends $47 \mathrm{~km}$ along the coast, incorporating a semi-continuous fringing reef, and four large areas of mangrove (Avicennia marina), sea-grass beds as well as inland coastal plain and mountain. Declared a protected area (under Law 102) in 1992, Nabq covers a total area of $586.5 \mathrm{~km}^{2} ; 121.9 \mathrm{~km}^{2}$ of these within the sea, as shown in Fig. (1). 


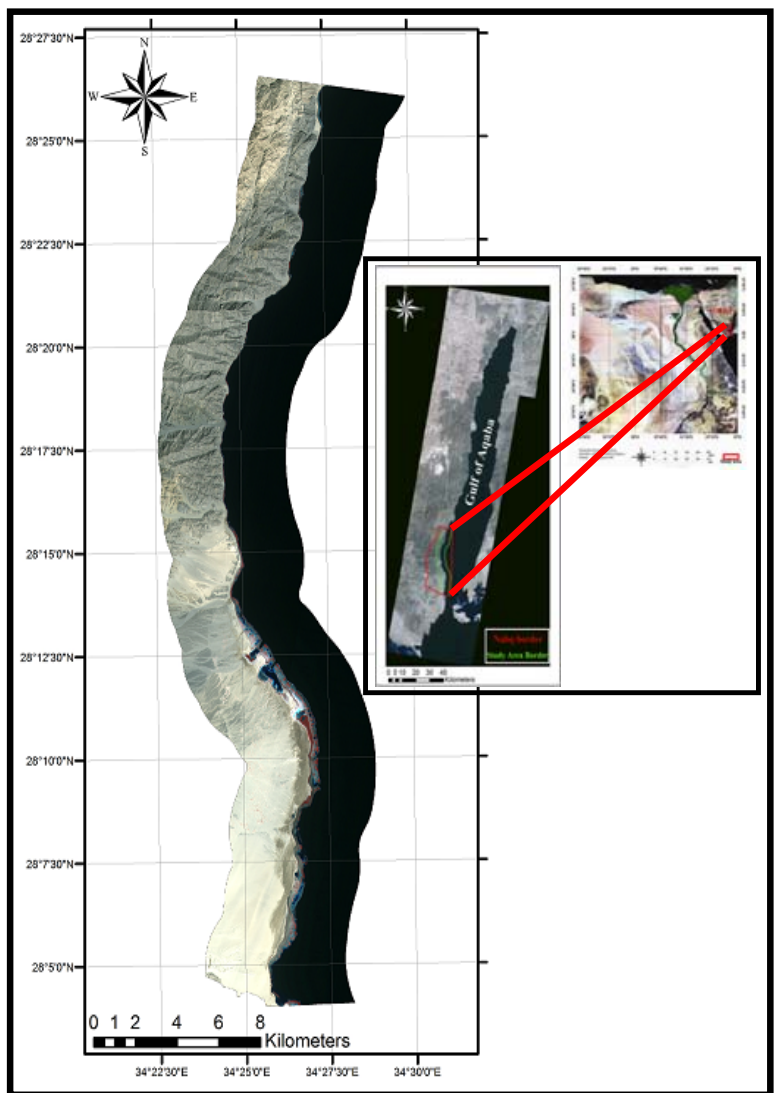

Fig. 1: A map shows a satellite imagery of the study area location

\section{Data sources}

\section{Satellite data:}

A group of seven imageries; six imageries of (SPOT-4) satellite beside one imagery of (Quick-Bird) satellite were selected, depending on the data availability in NARSS archiving system about the study area and we have chosen the (SPOT- 4 and Quick-Bird) satellite imageries because the specifications of the imageries (spectral and spatial) are meeting the needs and purpose of the objectives of the work; (SPOT4 and Quick-Bird) sensors have several spectral bands and the scale ground resolutions of these imageries $(10 \mathrm{~m}$ and $0.6 \mathrm{~m})$ respectively, are suitable for the objectives of this work. Table (1) shows a list of the used imageries in the presented study (Earth Observation Satellite Company 2007).

Table 1: list of Available imageries used in the present study

\begin{tabular}{|l|l|c|c|}
\hline No. & \multicolumn{1}{|c|}{ Imagery Type } & Path / Row & Date \\
\hline 1 & SPOT - 4 (Pan) + (XS) & $119 / 293$ & $13 / 05 / 2006$ \\
\hline 2 & SPOT - 4 (Pan) + (XS) & $119 / 293$ & $04 / 09 / 2009$ \\
\hline 3 & SPOT - 4 (Pan) + (XS) & $120 / 293$ & $27 / 04 / 2010$ \\
\hline 4 & Quick - Bird & Shp file & $\mathbf{2 7 / 0 9 / 2 0 1 0}$ \\
\hline
\end{tabular}

\section{Data preparation:}

Each (SPOT-4) imagery has been geometrically rectified onto a common projection; Universal Transverse Mercator (UTM) with (WGS 84) datum and Zone 36 
North; and the geometric model used in the rectification process was second order polynomial and the resembling method is the nearest neighbor method (image to image registration) with total RMS equals (0.0109), using ERDAS v.10 software. Then each (SPOT-4) imagery was Radio-metrically balanced using ENVI software v. 4.8 , then Data merge technique was performed to enhance the ground resolution of (SPOT-4) imageries by merging the low-resolution multi-spectral imagery, with highresolution gray scale imagery; using ENVI software v. 4.8, then Imagery mosaicking was performed using ENVI software v. 4.8; while the (Quick-Bird) imagery didn't go through the past processes because it was delivered done already; and finally each imagery was spatially sub-set to study area using Area of Interest cropping method, to remove portions of the image that are unnecessary for analysis, and reduce processing time; spatial subset was applied using ENVI software v. 4.8.

\section{Data processing:}

The research involved two main steps. In the first step, classification of satellite data carried out. The second step concentrated on the change detection analysis. Analysis of satellite data includes registration; classification and change detection using post classification comparison that carried out using ENVI and GIS software.

\section{Imagery classification:}

Imagery classification is perhaps the most important part of digital image analysis. It is very nice to have a "pretty picture" or an image, showing a magnitude of colors illustrating various features of the underlying terrain, but it is quite useless unless to know what the colors mean (PCI 1997).

Unsupervised and supervised classifications were conducted for each imagery to determine different zones (or classes) based on the spectral response.

ISODATA unsupervised classification was performed on the four imageries in ENVI 4.8, the desired number of output classes was set to 15-30, the maximum iteration count was set to 50, and the minimum number of pixels in each class was set to 20 .

Unsupervised classification was performed on the four imageries dated (2006, 2009 and 2010), yielding (19, 20 and 20) classes respectively per working area.

Due to the objectives of this research, and in order to speed up the habitat discrimination process, it was decided to drop terrestrial habitats. Therefore, classes corresponding to terrestrial habitats were merged into one class; so were classes corresponding to deep marine water; the other classes remains inside the target area (8, 9 and 9 classes) for years (2006, 2009 and 2010) respectively.

Using the output classes from the unsupervised classification, and the Random Stratified Sampling utility in ENVI 4.8, total of (270) ground-truth points over (9) classes were generated for recognizing these classes and guiding multispectral classification, total of (30) points for each class were obtained according to Congalton (1991), then supervised classification was performed on these data.

Among different decision rules which can be applied in a supervised classification methodology, we selected the Maximum Likelihood in the classification; Maximum Likelihood Classifier (MLC) has proven to be the most robust classifier in the field of Remote Sensing, as long as spectral information in each class calculated clearly (Benfield et al., 2005), especially for mapping and monitoring wetlands and coastal areas, supervised maximum likelihood classification considered the most commonly used technique (Ozesmi and Bauer, 2002).

\section{Change detection analysis:}

Change detection is the process of identifying differences in the state of an object or observing it at different times. Essentially, it involves the ability to quantify 
temporal effects using multi-temporal data sets. Change detection analysis was executed in ENVI 4.8 according to (Xingping Wen, 2009).

\section{Field data:}

Two field surveys have been completed between March $26^{\text {th }}$ and April $4^{\text {th }} 2012$, and between August $25^{\text {th }}$ and August $31^{\text {st }}$ 2012. During these campaigns, (420) observations were done at sea. $\mathrm{X}$ and $\mathrm{Y}$ coordinates were measured using a GPS (Garmin GPS 12 XL) in the (UTM) with (WGS 84) datum and Zone 36 North coordinate system. The positional error on the GPS-readings was in the order of 3 to $4 \mathrm{~m}$. Depth values were derived using hand-held sonar (Manta Dive Ray DR-100) with an accuracy of $0.3 \mathrm{~m}$ above and $1.0 \mathrm{~m}$ below $10 \mathrm{~m}$. A Zodiac was used so as to reach shallow areas.

\section{Accuracy assessment:}

Map accuracy was assessed using an error matrix, a measure of overall accuracy and Kappa analysis to provide comprehensive information on both overall accuracy and the user and producer accuracy of individual classes (Green et al., 2000).

However, if a user accuracy of $80 \%$ is obtained for coral reef, then the user can be sure that whenever that category is visited, there is an $80 \%$ probability that it will be coral reef (Congalton, 1991).

\section{Collection of accuracy assessment data:}

Although (Congalton 1991) suggests that 50 sites per class should be collected via simple random and stratified random sampling regimes, it was felt that as little as 30 points could be used for a relatively small area such as this study site. The position of each sampling point was noted, along with time, water depth (using a hand-held echo sounder) and an estimate of the spatial extent of the benthic class.

\section{RESULTS}

\section{Habitat classification:}

Unsupervised classification was performed on the 4 dated imageries (Fig. 2); followed by supervised classification based on the results of field observations using 270 identifying points (Fig.3; Table 2) and then an accuracy assessment was carried out using 150 ground control points that had been collected on the study area. The overall accuracy of the classification scheme was $84.7 \%$.

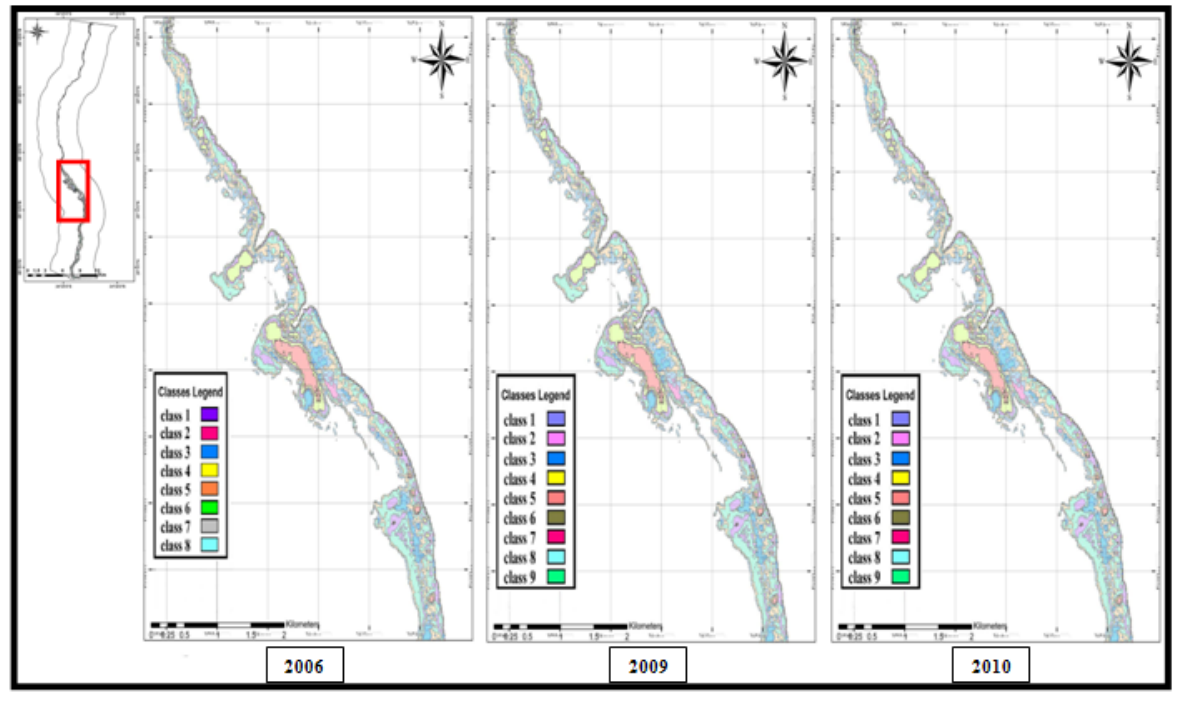

Fig. 2: Unsupervised Classification output for imagery dated 2006, 2009 and 2010. 
Table 2: The Unsupervised classification output classes which represent the coastal zone habitat for years 2006, 2009 and 2010 after recognizing the classes by field trip.

\begin{tabular}{|l|c|c|c|c|}
\hline Class No. & Habitat & 2006 & 2009 & 2010 \\
\hline Class 1 & Hard coral & $325 \mathrm{Ha}$ & $324.78 \mathrm{Ha}$ & $324.47 \mathrm{Ha}$ \\
\hline Class 2 & Soft coral & $19.27 \mathrm{Ha}$ & $19.27 \mathrm{Ha}$ & $19.27 \mathrm{Ha}$ \\
\hline Class 3 & Sea grass & $97.67 \mathrm{Ha}$ & $97.81 \mathrm{Ha}$ & $97.89 \mathrm{Ha}$ \\
\hline Class 4 & Rock & $147.345 \mathrm{Ha}$ & $147.345 \mathrm{Ha}$ & $147.345 \mathrm{Ha}$ \\
\hline Class 5 & Sand & $442.035 \mathrm{Ha}$ & $441.895 \mathrm{Ha}$ & $441.815 \mathrm{Ha}$ \\
\hline Class 6 & Deep water & $12812.02 \mathrm{Ha}$ & $12812.02 \mathrm{Ha}$ & $12812.02 \mathrm{Ha}$ \\
\hline Class 7 & Dead coral & -------- & $2200 \mathrm{~m}^{2}$ & $5300 \mathrm{~m}^{2}$ \\
\hline Class 8 & Mangrove trees & $49 \mathrm{Ha}$ & $49 \mathrm{Ha}$ & $49 \mathrm{Ha}$ \\
\hline Class 9 & Mangrove roots & $3.5 \mathrm{Ha}$ & $3.5 \mathrm{Ha}$ & $3.5 \mathrm{Ha}$ \\
\hline
\end{tabular}

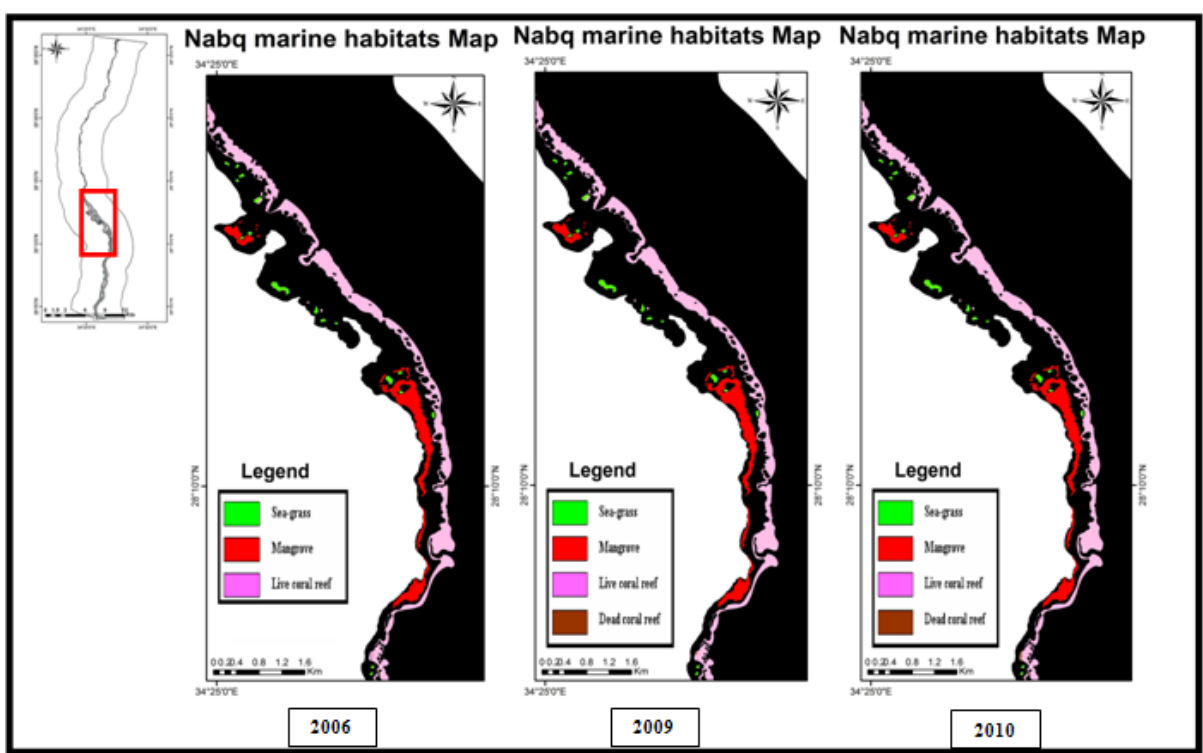

Fig. 3: Supervised Classification output based on the results of field observations for 2006, 2009 and 2010 .

\section{Change detection analysis for each marine habitat}

Table (2) shows the existed habitats at Nabq (MRPA) coastal zone and their areas and changes of each habitat in $(\mathrm{Ha})$. The change detection map is presented in Figure (3).

Table (3) and Figure (4) show the stability of mangrove area class from 2006 to 2010 is due to the descriptive resolution of the used sensor (SPOT-4) couldn't detect the fine changes that happened in mangrove stock through the study period; here comes the rule of (Quick-Bird) sensor, to detect theses fine changes with its fine resolution $(0.6 \mathrm{~m})$.

Table 3: The total area of each mangrove stand of the study area as calculated from the GIS map layer

\begin{tabular}{|l|l|l|l|l|}
\hline & \multicolumn{3}{|c|}{ (SPOT -4) } & Quick bird \\
\hline Location & 2006 & 2009 & 2010 & 2010 \\
\hline Al-Manquata & $7.1 \mathrm{ha}$ & $7.1 \mathrm{ha}$ & $7.1 \mathrm{ha}$ & $7.37 \mathrm{ha}$ \\
\hline Al-Rowaisseya & $27.6 \mathrm{ha}$ & $27.6 \mathrm{ha}$ & $27.6 \mathrm{ha}$ & $28.65 \mathrm{ha}$ \\
\hline Mersa,Abu.Zabad & $14.4 \mathrm{ha}$ & $14.4 \mathrm{ha}$ & $14.4 \mathrm{ha}$ & $14.95 \mathrm{ha}$ \\
\hline Al-Gharqana & $3.4 \mathrm{ha}$ & $3.4 \mathrm{ha}$ & $3.4 \mathrm{ha}$ & $3.53 \mathrm{ha}$ \\
\hline "scattered" & --------- & ---------- & -------- & $(500 \mathrm{~m} 2)$ \\
\hline
\end{tabular}




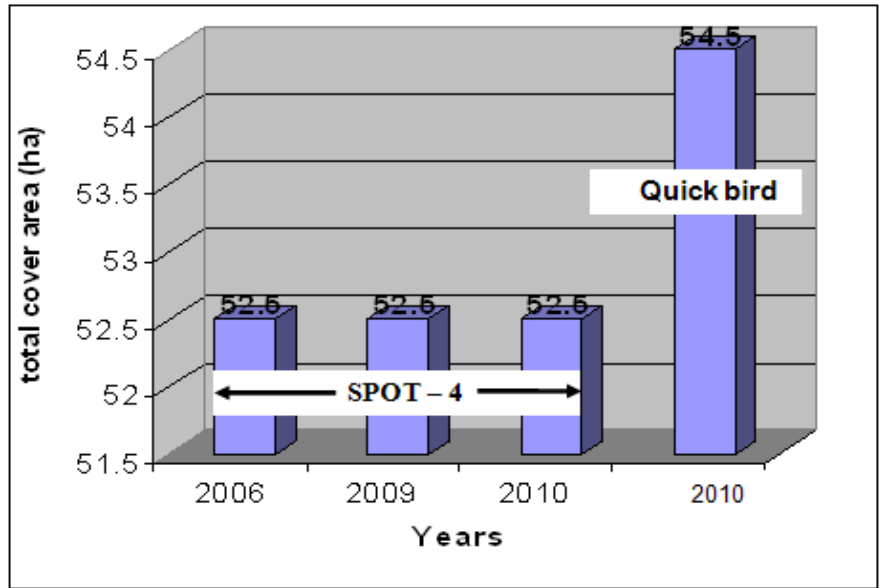

Fig. 4: The changes in the total cover area of Mangrove forests at Nabq coastal zone

Table (4) and Figure (5) show the increasing of sea grass beds is due to that this area is a protected area and lack of any anthropogenic activities that can harm the existing habitat or species; except in one place where the shrimp farm exists.

Table 4: The total cover area of Sea grass beds existing in Nabq (MRPA) coastal zone and monitoring of sea grass beds along the period from 2006 to 2010

\begin{tabular}{|l|c|l|}
\hline Year & Sea-grass area (ha) & Difference $(2006-2009-2010)$ \\
\hline 2006 & 97.67 & \\
\hline 2009 & 97.81 & $(2009-2006)=\left(+1400 \mathrm{~m}^{2}\right)$ \\
\hline 2010 & 97.89 & $(2010-2009)=\left(+800 \mathrm{~m}^{2}\right)$ \\
\hline
\end{tabular}

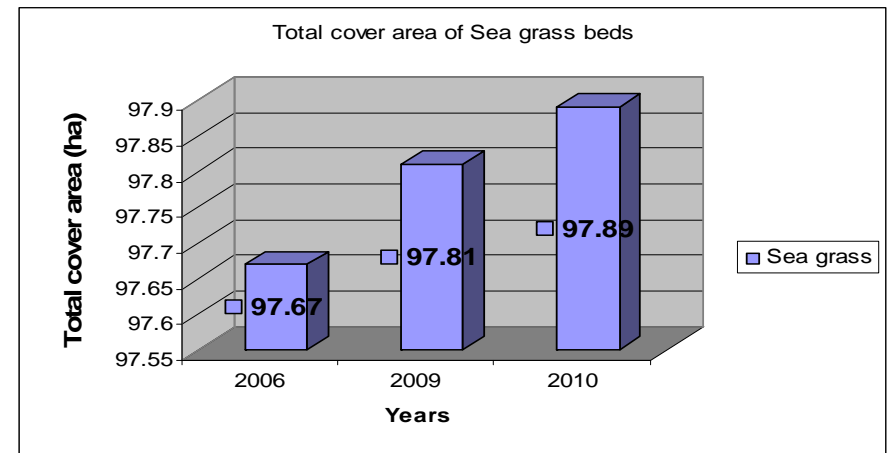

Fig. 5: The total cover area of Sea grass beds existing in Nabq (MRPA) coastal zone and monitoring of sea grass beds along the period from 2006 to 2010

Table (5) and Figure (6) show the decrease in the coral reef class from 2006 to 2010 is due to the direct action of the shrimp farm by charging the wastes directly into the sea water and existing coral reef causing the damage and degradation of living coral occupying area.

Table 5: The total cover area of coral reef (living \& dead) existing in Nabq (MRPA) coastal zone and monitoring coral reef along the period from 2006 to 2010.

\begin{tabular}{|l|l|l|}
\hline Year & Living Coral reef area (ha) & Dead coral (2006-2010) \\
\hline 2006 & 325.002 & \\
\hline 2009 & 324.782 & $(2009-2006)=\left(-2200 \mathrm{~m}^{2}\right)$ \\
\hline 2010 & 324.472 & $(2010-2009)=\left(-3100 \mathrm{~m}^{2}\right)$ \\
\hline
\end{tabular}




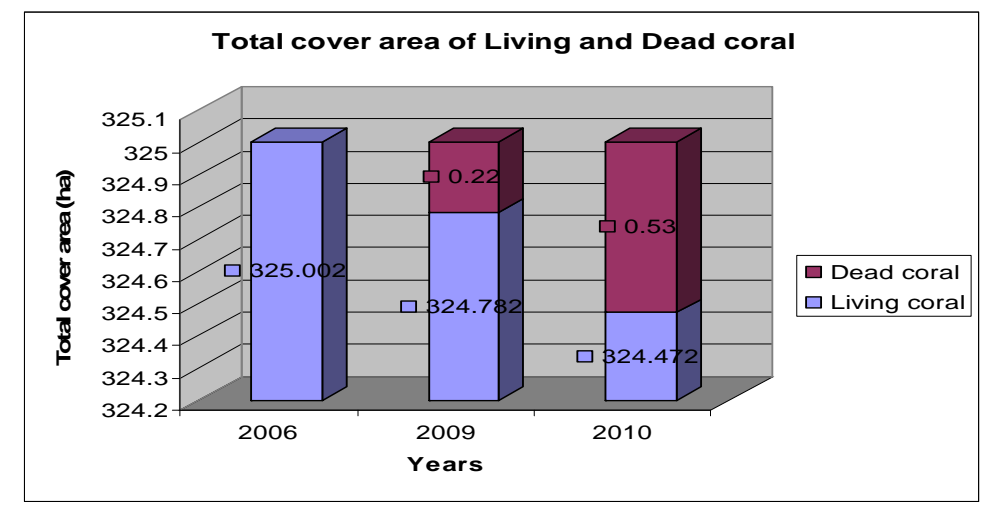

Fig 6: The total cover area and changes of living and dead coral reef existing in Nabq (MRPA) coastal zone along the period from 2006 to 2010

\section{Accuracy assessment:}

Accuracy assessment is a must to evaluate the accuracy of the land-use/cover produced map; to evaluate the accuracy of the land-use/cover map, a confusion matrix was produced; the results are given in the confusion matrix shown in Table (6).

The reading of the confusion matrix draws some comments. First of all, it can be noted that mangrove has been very well classified, especially since the two mangrove classes have been merged into one. This is not surprising as it is displayed with a characteristic spectral signature on the satellite imageries. The two points misclassified are found on coastal vegetation and are very close to mangrove vegetation.

Table 6: The confusion matrix of supervised classification and ground truth

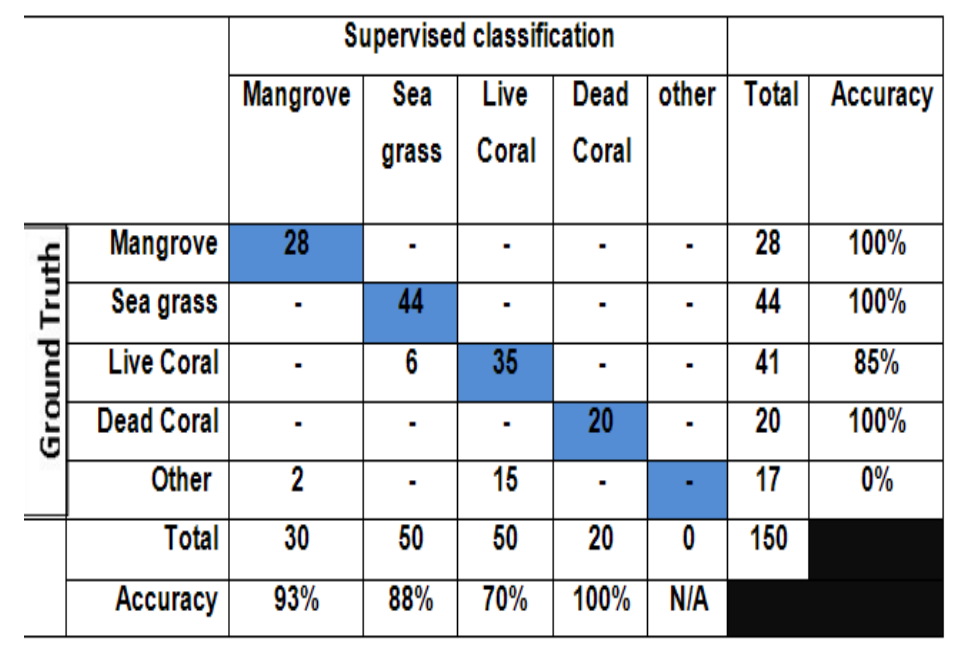

Based on Table (6) the Overall accuracy $=(28+44+35+20+0) / 150=(84.7 \%)$.

Another measure of map accuracy is (the kappa coefficient), which is a measure of the proportional (or percentage) improvement by the classifier over a purely random assignment to classes, for an error matrix with $r$ rows, and hence the same number of columns.

Where

$$
\left\lceil\widehat{\kappa}=\frac{N A-B}{N^{2}-B}\right]
$$

$\mathrm{A}=$ the sum of $\mathrm{r}$ diagonal elements, which is the numerator in the computation of overall accuracy 
$\mathrm{B}=$ sum of the $\mathrm{r}$ products (row total $\mathrm{x}$ column total).

$\mathrm{N}=$ the number of pixels in the error matrix (the sum of all individual cells) (Landis and Koch, 1977; Kundel and Polansky, 2003)

In the present study:

$\mathrm{A}=(28+44+35+20+0)=127$

$\mathrm{B}=(28 * 30)+(44 * 50)+(35 * 50)+(20 * 20)+(17 * 0)=5190$

$\mathrm{N}=150$

$$
\text { Thus } \widehat{\kappa}=\frac{N A-B}{N^{2}-B}=\frac{(150 \star 127)-}{(150 \star 150)-}=0.80 \text { (substantial) }
$$

Secondly, the confusion between 6 points of sea grass with living coral on the fore-reef can be explained by incorrect classification. Sea grass is occasionally confused spectrally with coral reef particularly where the latter include significant levels of algae; however, sea grass is not the found on the fore-reef, so sea grass patches on the fore-reef should be recoded as coral.

Thirdly, a similar explanation is also valid for the confusion between live coral and other substrates (rock or sand) include significant levels of turf algae, but we can't recode these 10 sites; we can only record them as wrong classification and Finally, the dead coral has been very well classified with a $100 \%$ correct.

\section{DISCUSSIONS AND CONCLUSIONS}

As we know; the nation's future is dependent on the wise and sustainable use of its natural resources, which are the basis for all economic activities in the country, the protection of the nation's natural resources becomes an absolute necessary; the protection of the nation's natural heritage dose not end with the declaration of Protected Areas, but it starts there. Protected Areas are nothing but pieces of paper and lines on a map without enforcement and effective management, in land use plans, in policies for resource utility and in development initiatives, which would mean giving them a greater chance for success and a lasting sustainable existence (Baha El Din, 1998).

Nabq Protected Area was established as a Managed Resource Protected Area (IUCN PA management category VI) in 1992 by the Law N. 102 of 1983, prime ministerial decree 1511 for 1992 declaration of the area, and declaration of the whole Gulf of Aqaba (Egyptian Side) a natural protectorate. Nabq (MRPA) is the biggest marine protectorate exists in the region and characterized by the great diversity of habitats and ecosystems in a uniquely compact setting, representing a complete terrestrial/marine ecosystem characteristic of the Gulf of Aqaba coast, having one of the northern-most mangrove Avicennia marina communities in the world, coral reefs and sea-grass (Mabrouk, 2007).

Satellite imagery has immensely helped mapping of coastal ecosystems and provided estimates of extent and alteration in land cover in coastal ecosystem. Information on coastal habitat (critical/vital) and associated shore land features along the entire coast has been carried out through visual interpretation of multi-spectral data for macro-level planning for many countries (Nayak et al., 1991; Jagtap et al., 2001; Nayak, 2002).

In the present study; we used a time series of four imageries; three (SPOT-4) imageries dated 2006, 2009 and 2010 beside one (Quick-Bird) imagery dated 2010 to 
map and monitor coastal zone habitats of Nabq and evaluate the causes of changes that happened in Nabq coastal zone habitats.

Depending on (SPOT - 4) imageries classifications only; the present study shows that there's no changes happened to the total cover area of Mangrove forests in Nabq (MRPA) during the period from 2006 to 2010, and the total cover area of Mangrove forests in Nabq (MRPA) is (52.5 ha), divided into four large stands their areas could be distinguish from north to south as follow: Al-Manquata (7.1ha), AlRowaisseya (27.6 ha), Mersa Abu Zabad (14.4 ha) and Al-Gharqana (3.4 ha).

This result totally agreed and confirmed the work of (GALAL, 2003) in which he stated that all Sinai mangroves were included within the territories of Nabq Protected Area and Ras Mohammed National Park, the mangrove stand at Shura AlManquata is considered as the northerly limit of the Western Indian Ocean Region, the total area of the stand was estimated as 7.1ha, and the largest stand in the group is Shura Al-Rowaisseya covering around 27.6ha, and the mangrove stand at Mersa Abu Zabad covers 14.4ha, and finally some Avicennia marina trees grow at the northeastern end of Al-Gharqana lagoon with total area covers 3.4 ha. But the question that may be raised: How could the total cover area of Mangrove in Nabq remain fixed without increasing or decreasing for (years)?

So, we had to use another sensor with higher "descriptive resolution" to obtain more details about Mangrove in the area. Depending on (Quick-bird) imagery classifications the results show that, the total cover area of Mangrove forests in Nabq is ( $54.5 \mathrm{ha})$, the total cover area of each stand could be distinguish from north to south as follow: Al-Manquata (7.37ha), Al-Rowaisseya (28.65ha), Mersa Abu Zabad (14.95ha) and Al-Gharqana (3.53ha), moreover; we found out $\left(500 \mathrm{~m}^{2}\right)$ of Mangrove shrubs scattered along the coast in 2010 .

On the other hand, the results of this research is completely away from the results stated by Ali A. Gab-Alla (2010) in which the author stated that; the total area of mangrove stand at Gharqana 0.29 ha, Abu Zabad 28.57 ha, Monqataa 13.95 ha and the largest mangrove in South Sinai located in Rowaiseya with an area of 53.67 ha.

The present study shows that the total cover area of sea grass estimated by (97.89 ha) distributed all over the sandy coastal zone and lagoons as the limit of light penetration that received by the sensor.

Unfortunately, none have mapped the sea grass beds at Nabq (MRPA) coastal zone before to compare the present result with his, but mapping and monitoring sea grass beds using Remote Sensing technology are widely used (Ganesan \& Kannan, 1995; Lee Long et al., 2000; Gullstrom et al., 2006; Jagtap et al., 2003 and Thangaradjou et al., 2008).

The present results confirmed that the sea grass beds are growing and spreading from year to year, where the total cover area of sea grass at (2006 was $97.67 \mathrm{ha}$ ) becomes at (97.81 ha in 2009) and finally (97.89 ha in 2010).

The present study shows that the coral reef is extend along almost the entire 47 $\mathrm{km}$ of coastline, broken in only occasional places by lagoons or small reef pools of the coastal zone of Nabq, the total cover area of living coral reef along the coastal zone of Nabq $($ MRPA $)=(324.472$ ha in 2010), the reef flat extents from narrow at the north of the protected area and going wider when going to the south.

The reef flat extents from 20 meters in some places at the north to about 450 meters at the southern part of the protected area, the percent of living coral must be equals or larger than $50 \%$ of the total cover of each quadrate taken in the present study. 
These results agreed with (Galal 1999) who reported that the coastal ecosystem of Nabq (MRPA) is dominated by fringing coral reefs that extend along almost the entire $47 \mathrm{~km}$ of coastline, broken in only occasional places by lagoons or small reef pools. The reef is well developed, with the fore-reef between $100 \mathrm{~m}$ and $800 \mathrm{~m}$ from the shore. Extensive reef-flats and back-reef lagoons are also present. The reef-flat of Nabq (MRPA) ranges in breadth from $50 \mathrm{~m}$ to $650 \mathrm{~m}$.

The present study shows that; the shrimp farm is responsible for the destruction of $2200 \mathrm{~m}^{2}$ of living coral at 2009 , and another $3100 \mathrm{~m} 2$ added to the dead coral at 2010 , to become $5300 \mathrm{~m}^{2}$ of dead coral by the time of imagery taken on $27^{\text {th }}$ of April 2010.

The completely dead coral reef area was existed near to the southern part of the Experimental Shrimp Farm, the coral was covered by (cattle manure) which used in the Experimental Shrimp Farm (as fertilizers) and then released and drained directly into the sea via the deflation pipe which kept releasing directly into the sea and the destruction to the environment kept expanding more and more; as a result, the cattle manure sank down on whatever is at the sea bottom however it's coral or sand or rock and killed $5300 \mathrm{~m}^{2}$ of existed coral reef.

The current study proved that the use of Remote Sensing and Geographical Information System could generate status map, not only for the existing habitats at the present time, but also for the changes which could be resulted from anthropogenic activities or natural causes performed in a large scale. So, remote sensing can play a vital rule in reducing the cost, labor, time required to develop state wide protected areas assessments that are currently very difficult by using traditional field operations.

\section{REFERENCE}

Baha El Din, (1998). Towards establishing a network Plan for Protected Areas in Egypt. Report to NCS, EEAA.

Benfield, S.L., Guzman, H. M., and Mair, J.M. (2005). Temporal mangrove dynamics in relation to coastal development in Pacific Panama. Journal of Environmental Management, 76(3): 263-276.

Chiffings, T. (2003). A Global Representative System of Marine Protected Areas. Marine Region 11, Arabia Seas.

Congalton, R.G., (1991). A review of assessing the accuracy of classifications of remotely sensed data. Remote Sensing of Environment, 37: 35-46.

Earth Observation Satellite Company, (2007)."SPOT system status report" September 2007: Lanham, Md., Earth Observation Satellite Company.

Green, E.P, Mumby, P.J., Edwards A.J., Clark, C.D., (Ed. A.J. Edwards). (2000). Remote sensing handbook for tropical coastal management. Coastal Management Sourcebooks 3, UNESCO, Paris.

Jagtap, T. G.; Nayak, S. and Nagle, V. L. (2001). Assessment of coastal wetland resources of central west coast, India using Landsat data. Jour. Ind. Soc. Remote Sens., 29 (3): 143-150.

Kundel HL, Polansky M. (2003). Measurement of Observer Agreement. Radiology, 228:303-8

Landis RJ, Koch GG. (1977). The measurement of observer agreement for categorical data. Biometrics 33:159-174.

Mabrouk, A. (2007). Management Plan for NMRPA. Nature Conservation Sector, NCS-UNEP. 
Nayak, (2002). Use of satellite data in coastal mapping. Indian Cartographer, 22: 147-156.

Nayak, S. (1991). Manual for mapping of coastal wetlands/land forms and shoreline changes using satellite data. Technical Note, Space Applications Centre, Ahmedabad. IRS-UP/SAC/MCE/SN/32/91:63pp.

Ozesmi, S. L. and Bauer, M. E. (2002). Satellite remote sensing of wetlands. Wetlands Ecology and Management, 10:381-402.

PCI, (1997). PCI 7.0.1. Image analysis software, Help Menu. PCI, Toronto, Canada.

PERSGA Technical Series No. 10, June (2004). (accessed 12 Feb, 2012-7:05 pm)

Xingping W. (2009). "A new change detection method for two remote sensing images based on spectral matching" Xiaofeng Yang Industrial Mechatronics and Automation, ICIMA 2009. International Conference, 15-16: 89-95.

\section{ARABIC SUMMARY}

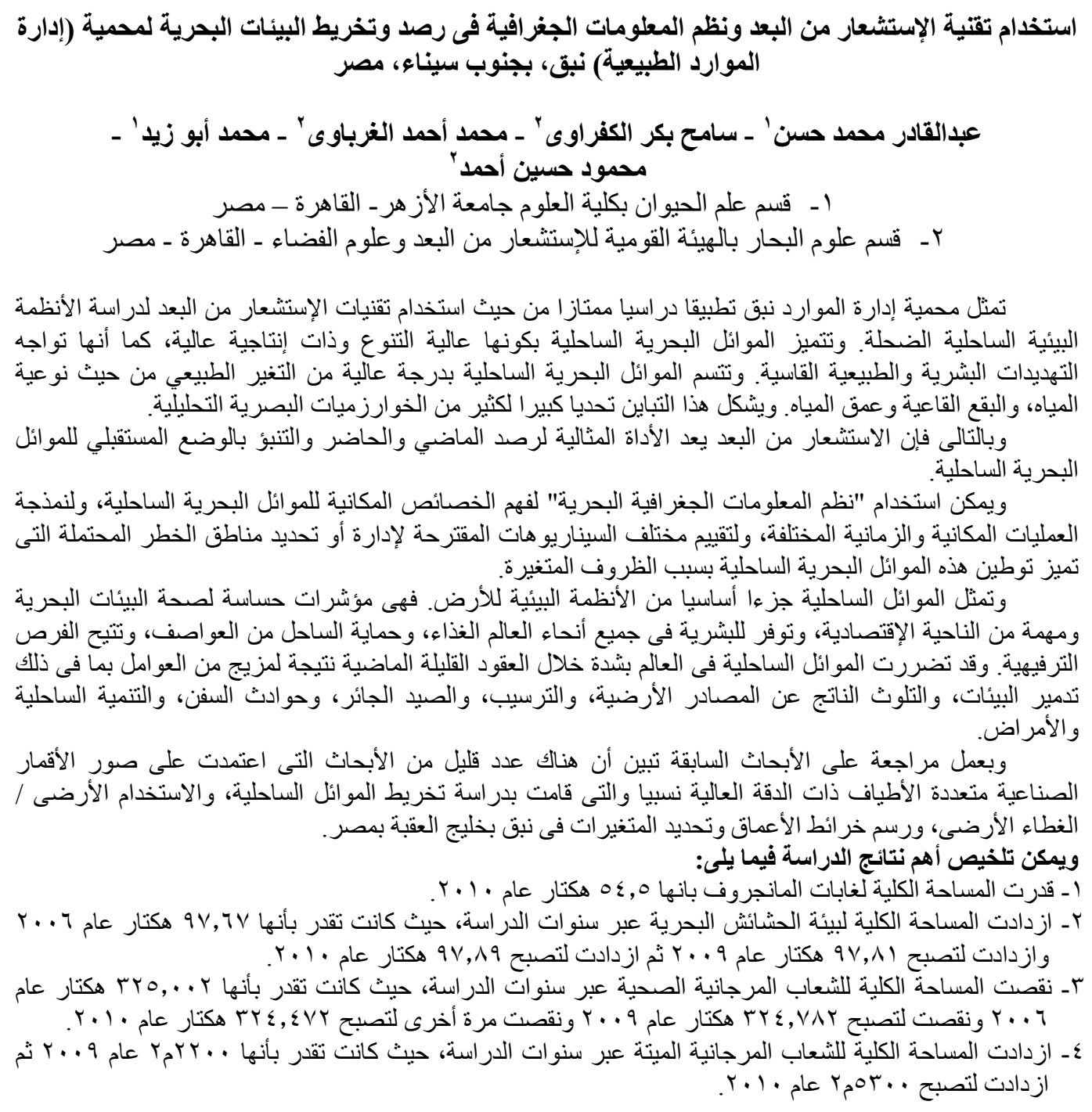

